\title{
The rapid identification of lactic acid bacteria present in Chilean winemaking processes using culture-independent analysis
}

\author{
Carolina Ilabaca $\cdot$ Carla Jara $\cdot$ Jaime Romero
}

Received: 13 August 2013 / Accepted: 9 January 2014 / Published online: 25 January 2014

(C) The Author(s) 2014. This article is published with open access at Springerlink.com

\begin{abstract}
A polymerase chain reaction-restriction fragment length polymorphism (PCR-RFLP) analysis of $16 \mathrm{~S}$ ribosomal RNA (rRNA) genes was developed to identify lactic acid bacteria $(\mathrm{LAB})$ that are commonly present in winemaking processes (Oenococcus, Pediococcus, Lactobacillus, and Leuconostoc). This culture-independent approach revealed the presence of Oenococcus in the spontaneous malolactic fermentation in industrial Chilean wines.
\end{abstract}

Keywords Malolactic fermentation - Oenococcus oeni . Lactic acid bacteria $\cdot$ Wine $\cdot$ Chile

In Chile, the production of wines has sharply increased in recent years, reaching 12.5 million $\mathrm{hL}$ per year (Servicio Agrícola y Ganadero, Chile 2012). In most Chilean wineries, the malolactic fermentation (MLF) stage of winemaking largely occurs in a spontaneous manner; thus, at present, limited knowledge exists regarding the bacterial populations involved in this process. MLF is an important stage impacting the wine quality, in which lactic acid bacteria (LAB) transform malic acid into lactic acid and $\mathrm{CO}_{2}$, decreasing the overall acidity of a wine and proving microbiological stability. Hence,

Electronic supplementary material The online version of this article (doi:10.1007/s13213-014-0810-6) contains supplementary material, which is available to authorized users.

C. Ilabaca $\cdot$ J. Romero $(\bowtie)$

Laboratorio de Biotecnología, Instituto de Nutrición y Tecnología de los Alimentos (INTA), Universidad de Chile, El Líbano,

5524 Macul Santiago, RM, Chile

e-mail: jromero@inta.cl

C. Jara

Departamento de Agroindustria y Enología, Facultad de Ciencias

Agronómicas, Universidad de Chile, Av. Santa Rosa,

11315 La Pintana, Santiago, RM, Chile this study aimed to develop a rapid molecular method to describe LAB populations during spontaneous MLF.

A succession of LAB is observed during spontaneous MLF. In particular, LAB belonging to the genera Lactobacillus, Leuconostoc, Oenococcus, and Pediococcus have been found in wine (Lonvaud-Funel 1999; Reguant and Bordons 2003; Ruiz et al. 2010). Lactobacillus, Pediococcus, and Leuconostoc species gradually disappear as vinification proceeds. In contrast, Oenococcus oeni becomes increasingly apparent during the course of MLF (Spano et al. 2007). This dynamic of bacterial populations present during MLF has been studied using culture-dependent techniques (Reguant and Bordons 2003). These bacteria grow slowly in artificial media; as a result, the isolation of these bacteria requires long incubation times ( $>5$ days), and the biochemical identification of these bacteria is tedious because it depends on the growth of the cultured strains. Therefore, these methods are unsuitable for the practical monitoring of bacteria during industrial vinification. Furthermore, it is challenging to utilize these methods to obtain an accurate picture of the dynamics of LAB during MLF because these bacteria generally exhibit low cultivability (Amann et al. 1995; Hugenholtz et al. 1998).

More recently, molecular methods based on analyzing DNA extracted from a sample (culture-independent methods) have been employed to circumvent this issue. Renouf et al. (2006) and Spano et al. (2007) applied denaturing gradient gel electrophoresis (DGGE) to the analysis of bacterial populations during MLF. This method is difficult to utilize routinely because the achievement of reproducible gradients using DGGE requires relatively sophisticated equipment and trained personnel. In this work, a cultureindependent analytical approach is proposed that requires only simple equipment and can provide rapid results regarding the composition of bacterial populations present during industriallevel MLF. In this method, Oenococcus, Leuconostoc, Pediococcus, and Lactobacillus bacteria are identified using 
a polymerase chain reaction-restriction fragment length polymorphism (PCR-RFLP) approach that involves two restriction enzymes. This approach allows for the simultaneous determination of the presence or absence of the four most prevalent winemaking LAB genera in MLF during vinification.

The design of this MLF tracking method involved approximately $500 \mathrm{bp}$ of the $16 \mathrm{~S}$ ribosomal RNA (rRNA) gene sequences of the Oenococcus, Leuconostoc, Pediococcus, and Lactobacillus genera; in particular, numbering base pairs based on the Escherichia coli. 16S rRNA gene, the region between base pairs 341 and 788 was examined (Figure S1). These sequences were aligned with ClustalW (Larkin et al. 2007) and subjected to an entropy analysis to determine regions that differentiated the examined genera. Four such regions, located approximately at base pairs 456-461, 616621, 651-656, and 766-771, were identified through this analysis; these regions are useful for using 16S rRNA gene analysis to distinguish among these four winemaking $\mathrm{LAB}$ genera.

The in silico design for the MLF tracking approach required the identification of restriction endonucleases that recognized sites within these regions. This search was performed using the BioEdit software program, version 7.1.3 (Hall 1999). Finally, two enzymes, $X m n I$ and $T_{s} p$ RI, were selected. The simultaneous use of both enzymes produced distinctive restriction patterns that differentiate among the examined winemaking LAB. Comparing the in silico with the experimental restriction profiles of reference strains allowed the validation of the method to distinguish LAB populations. The reference strains from different collections were Oenococcus oeni JCM (Japan Collection of Microorganisms) 6125; Leuconostoc mesenteroides LMG (Laboratorium voor Microbiologie) 8159; Pediococcus parvulus NBRC (NITE Biological Research Center) 100673; and Lactobacillus brevis ATCC (American Type Culture Collection) 14687. To perform these comparisons, reference strains were grown in defined culture media, and DNA was extracted in accordance with Romero et al. (2002). The 16S rRNA gene was then amplified by PCR in accordance with Ilabaca et al. (2008). A combination of the restriction enzymes XmnI (Thermo Scientific) and $T_{s} p \mathrm{RI}$ (Thermo Scientific), which were chosen based on the in silico analysis, was used for amplicon digestion. Amplicons were incubated with these restriction enzymes for $2 \mathrm{~h}$ at $37^{\circ} \mathrm{C}$ and $16 \mathrm{~h}$ at $65^{\circ} \mathrm{C}$. The obtained restriction profiles were visualized using $90 \mathrm{~min}$ of electrophoresis at $80 \mathrm{~V}$ on $10 \%$ polyacrylamide gels followed by staining with SYBR Green (Invitrogen).

The results obtained from these analyses are depicted in Fig. 1. The reference strains exhibit different profiles following digestion with the tested enzymes. These restriction enzymes, XmnI and $T s p$ RI, provide results that are easy to visualize. In particular, a laddered pattern of restriction fragments

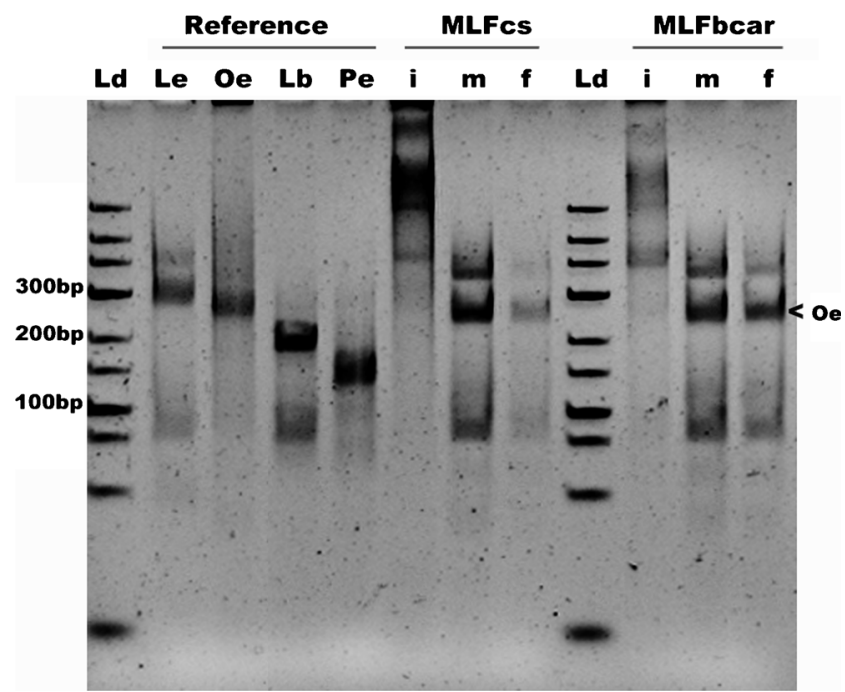

Fig. 1 RFLP profiles derived from reference strains and illustrating the identification of LAB during the MLF stages of the production of Cabernet Sauvignon (cs) and Carménère (car). The reference strains (Reference) correspond to Leuconostoc mesenteroides LMG 8159 (Le), Oenococcus oeni JCM 6125 (Oe), Lactobacillus brevis ATCC 14687 (Lb), and Pediococcus parvulus NBRC 100673 (Pd). The analyzed samples correspond to the following MLF stages: the initial stage (i), the middle stage $(\mathrm{m})$, and the final stage (f). Ld represents the O'GeneRuler Low Range DNA Ladder

is observed, with bands appearing at approximately $300 \mathrm{bp}$ for Leuconostoc, $250 \mathrm{bp}$ for Oenococcus, $200 \mathrm{bp}$ for Lactobacillus, and $150 \mathrm{bp}$ for Pediococcus. The exact sizes of the fragments are described in Table S1, it also describes that same genus always shows the same RFLP pattern.

The developed method was applied to wine samples during the MLF process. Spontaneous industrial MLF was monitored for Vitis vinifera cv. Cabernet Sauvignon and cv. Carménère (10,000 L). Different stages of the MLF process were examined: the initial stage of MLF (the iMLF lanes; this stage coincides with the end stage of alcoholic fermentation); the middle stage of MLF (the MMLF lanes), and the final stage of MLF (the fMLF lanes). For Cabernet Sauvignon, the initial stage of MLF was May 7, the middle stage of MLF was Jun 13, and the final stage of MLF was Jun 28. For Carménère, the initial stage of MLF was May 30, the middle stage of MLF was Jun 20, and the final stage of MLF was Jul 14. In the iMLF lanes (Fig. 1), the bands produced from samples of both cultivars do not correspond to bands produced by the $\mathrm{LAB}$ that are reportedly associated with MLF. This phenomenon may reflect the fact that only a limited LAB population is present during the initial stages of MLF; thus, this population may be below detection limits (Ruiz et al. 2010). In contrast, at the midpoint of MLF, the mMLF lanes for the examined cultivars exhibited bands indicative of the presence of Oenococcus. The presence of Oenococcus was also observed during the final stage of MLF (the AMLF lanes) for the examined cultivars. To confirm the identity of Oenococcus 
band, specific primers (F: GCTAAATACGTGCCAGCAGC; $\mathrm{R}$ : TCCACTTGCCTCTATCGCAC) were design and the band was eluted and sequenced; the resulting sequence corresponded to Oenococcus with $100 \%$ of identity as derived from Blast analysis (see Figure S2). In summary, the profiles revealed the prevalence of Oenococcus during the MLF process, and bacteria from this genus were readily differentiable from the other genera involved in MLF.

Based on the aforementioned results, the designed 16S rRNA PCR-RFLP strategy constitutes a fast, easy, informative and reliable tool for the identification and differentiation of winemaking LAB strains isolated during MLF processes. The proposed approach can distinguish among LAB genera reported to be present during MLF (Lonvaud-Funel et al. 1991; Bon et al. 2009; Ruiz et al. 2010). Consequently, the 16S rRNA PCR-RFLP approach using $X m n \mathrm{I}$ and $T_{s} p \mathrm{RI}$ allows for the simultaneous parallel observation of the presence or absence of the four genera (Oenococcus, Leuconostoc, Pediococcus, and Lactobacillus) of LAB that are most prevalent during the middle and final stage of MLF. This strategy can be used in both spontaneous MLF and MLF induced with commercial starter cultures. Thus, this qualitative method allows the genera of LAB involved in spontaneous MLF to be determined. In the case of MLF inoculated with commercial starter cultures, the introduction of the inoculated bacteria can be controlled, and any contamination by other winemaking LAB strains, which could alter the organoleptic characteristics of a wine, can be monitored.

Acknowledgments This was funded by grants from FONDEF Idea CA12I10123, Inserción a la Academia 791100011 and FONDECYT 1121329 from CONICYT; INNOVA 12IDL2-13145 from Corfo.

Open Access This article is distributed under the terms of the Creative Commons Attribution License which permits any use, distribution, and reproduction in any medium, provided the original author(s) and the source are credited.

\section{References}

Amann RI, Ludwig W, Schleifer KH (1995) Phylogenetic identification and in situ detection of individual microbial cells without cultivation. Microbiol Rev 59:143-169

Bon E, Delaherche A, Bilhère E, De Daruvar A, Lonvaud-Funel A, Le Marrec C (2009) Oenococcus oeni genome plasticity is associated with fitness. App Environ Microbiol 75:2079-2090

Hall T (1999) BioEdit: a user-friendly biological sequence alignment editor and analysis program for Windows 95/98/NT. Nucl Acids Symp Series 41:95-98

Hugenholtz P, Goebel BM, Pace NR (1998) Impact of culture independent studies on the emerging phylogenetic view of bacterial diversity. J Bacteriol 180:4765-4774

Ilabaca C, Navarrete P, Mardones P, Romero J, Mas A (2008) Application of culture culture-independent molecular biology based methods to evaluate acetic acid bacteria diversity during vinegar processing. Int J Food Microbiol 126:245-249

Larkin M, Blackshields G, Brown NP, Chenna R, McGettigan PA, McWilliam H, Valentin F, Wallace IM, Wilm A, Lopez R, Thompson JD, Gibson TJ, Higgins DG (2007) Clustal W and Clustal X version 2.0. Bioinformatics 23:2947-2948

Lonvaud-Funel A, Joyeux A, Ledoux O (1991) Specific enumeration of lactic acid bacteria in fermenting grape must and wine by colony hybridization with no- isotopic DNA probes. J Appl Bacteriol 71: 501-508

Lonvaud-Funel A (1999) Lactic acid bacteria in the quality improvement and depreciation of wine. J Anton Leeuw Int 76:317-331

Reguant C, Bordons A (2003) Typification of Oenococcus oeni strains by multiplex RAPD-PCR and study of population dynamics during malolactic fermentation. J Appl Microbiol 95:344-353

Renouf V, Claisse O, Lonvaud-Funel A (2006) Lactic acid bacteria evolution during winemaking: Use of $r p o B$ gene as a target for PCR-DGGE analysis. Food Microbiol 23:136-145

Ruiz P, Izquierdo PM, Sesena S, Palop ML (2010) Analysis of lactic acid bacteria populations during spontaneous malolactic fermentation of Tempranillo wines at five wineries during two consecutive vintages. Food Control 21:70-75

Romero J, Garcia-Varela M, Laclette JP, Espejo RT (2002) Bacterial 16S rRNA gene analysis revealed that bacteria related to Arcobacter spp. constitute an abundant and common component of the oyster microbiota (Tiostrea chilensis). Microbial Ecol 44:365-371

Servicio Agrícola y Ganadero (S.A.G.) (2012) Informe Ejecutivo Producción de Vinos Chilenos.http://www.sag.cl/sites/default/files/informe ejecutivo_produccion_vinos_2012.pdf Accessed 26 June 2013

Spano G, Lonvaud-Funel A, Claisse O, Massa S (2007) In vivo PCRDGGE analysis of Lactobacillus plantarum and Oenococcus oeni populations in red wine. Curr Microbiol 54:9-13 